CONSEJO DE ESTADO 



\title{
PROSTITUCIÓN, ANUNCIOS PUBLICITARIOS Y PRINCIPIOS CONSTITUCIONALES
}

\author{
RICARDO MARTIIN MORALES \\ Profesor Titular de Derecho Constitucional \\ Universidad de Granada
}

\author{
SUMARIO. \\ I. Introducción. \\ II. Insuficiencia de la actual normativa. \\ III. La cuestión de fondo. \\ IV. Derechos y principios constitucionales. \\ V. La prostitución en el ordenamiento infracons- \\ titucional español. \\ VI. ¿Es la dicotomía recomendable/no recomen- \\ dable de naturaleza jurídica? \\ VII. Comentario.
}

\section{INTRODUCCIÓN}

La Comisión de Estudios del Consejo de Estado, en su informe de 9 de marzo de 2011, ha llegado a la conclusión de que es acorde con el Derecho español «la adopción de medidas que coadyuven a la limitación de la publicación de anuncios de prostitución» ${ }^{1}$, no sin antes reconocer que el ámbito más adecuado para resolver esta cuestión hubiera sido la autorregulación y de recordar que los esfuerzos en este sentido ${ }^{2}$ han resultado insuficientes.

1 El Informe consta de siete apartados: I. Antecedentes. II. Objeto del estudio determinado por el encargo III. Consideraciones generales sobre la prostitución IV. Insuficiencia de la actual normativa española sobre publicidad para prohibir la de la prostitución V. Posibilidad de establecer la prohibición de la publicidad de la prostitución en la prensa escrita VI. Consideraciones sobre el proyecto de ley a elaborar VII. Consideración final.

2 Se han obtenido algunos avances en la autorregulación, como por ejemplo en la Declaración de Madrid de 4 de junio de 2010, donde los editores asumieron el compromiso de promover «altos estándares éticos en la autorregulación de la publicidad». 
El encargo parte de la que era en ese momento Ministra de Igualdad (Orden de 12 de mayo de 2010). Se le plantea al Consejo de Estado la viabilidad jurídica de una iniciativa dirigida a limitar o prohibir los anuncios publicitarios de contenido sexual y prostitución en la prensa escrita.

El exhaustivo informe elaborado por el Consejo de Estado se circunscribe a la publicidad de la prostitución en la prensa escrita, quedando por tanto excluidos de su objeto de estudio los anuncios de publicidad en otros medios. Ello no impide que a lo largo del informe se vaya pronunciando también el Consejo sobre la publicidad en otros soportes, particularmente en internet, casi siempre para subrayar la escasa eficacia, a estas alturas, de una restricción de la publicidad de la prostitución ceñida exclusivamente a la prensa escrita.

\section{INSUFICIENCIA DE LA ACTUAL NORMATIVA}

Precisamente el apartado IV del informe lleva esta rúbrica: «Insuficiencia de la actual normativa española sobre publicidad para prohibir la de la prostitución». Considera el Consejo de Estado que la regulación actualmente existente en España es insuficiente para prohibir, con carácter general, la publicidad de la prostitución en la prensa escrita. Sólo disponiendo de una normativa legal diferenciada de la actual legislación general en materia de publicidad se podría — advierte el Consejo de Estadoaplicar la prohibición ${ }^{3}$.

Esa disposición legal debería establecer de manera terminante que queda prohibida la publicidad de la prostitución y precisar «un concepto funcional de publicidad de la prostitución», esto es, «un concepto de publicidad a los efectos de la propia disposición legal». Dentro de dicho concepto quedaría comprendida «la inserción o exhibición de anuncios publicitarios que ofrezcan servicios sexuales mediante contraprestación económica, que informen sobre los locales en los que se ofrecen dichos servicios o inciten directa o indirectamente al tráfico carnal o al comercio sexual mediante precio».

\section{LA CUESTIÓN DE FONDO}

Para un constitucionalista la cuestión de fondo es la siguiente: si la prostitución ejercida libre y voluntariamente por personas mayores de edad no es ilícita, y si, por otra parte, y como es lógico, la publicidad es una actividad económica legal, ¿sobre qué fundamento se puede erigir una prohibición de los anuncios de prostitución?

La situación en la que nos encontramos es parecida a las limitaciones publicitarias de otros productos legales como el tabaco o el alcohol, si bien en estos dos últimos casos se

3 Como es sabido, el Estado es competente para dictar una ley de este tipo, de acuerdo con el artículo 149.1.27 ${ }^{\mathrm{a}} \mathrm{CE}$, que le reconoce la competencia para aprobar las «normas básicas del régimen de prensa, radio y televisión y, en general, de todos los medios de comunicación social, sin perjuicio de las facultades que en su desarrollo y ejecución correspondan a las Comunidades Autónomas». 
produce una importante afectación de la salud que no se aprecia, en principio, en el caso de los anuncios de contenido sexual.

Cuando entra el informe a tratar los límites de la actividad publicitaria, habla de que «la idea de valor comporta un afán de realización». Por ello, aunque el ordenamiento tolere situaciones contrarias a los valores que sustentan una comunidad, «no tiene por qué ser neutral ante ellas» y «puede reaccionar limitando su existencia o mitigando su propagación».

\section{DERECHOS Y PRINCIPIOS CONSTITUCIONALES}

\section{IV.1. LA DIGNIDAD}

No hay bien jurídico que dé mejor rendimiento dogmático en materia de prostitución que la dignidad (art. 10 CE). Si la relación entre prostitución y dignidad es evidente, también lo es la concepción de la dignidad como límite de la actividad publicitaria.

Los anuncios periodísticos de servicios sexuales afectan esencialmente a la dignidad de la persona cuyos servicios se ofrecen. Como es sabido, la naturaleza jurídica de la dignidad es, a pesar de no estar expresamente contemplada en el artículo 1.1 CE, la de un valor superior, que tiene que ver con la no instrumentación de la persona y con su no patrimonialización (STC 212/1996), esto es, con la no consideración de la persona como un mero objeto, en este caso sexual.

\section{IV.2. LA IGUALDAD DE GÉNERO}

A la Orden de 12 de mayo de 2010 acompañaba un documento rubricado «Estado de la situación y posibles actuaciones contra anuncios de contenido sexual y prostitución» de la Vicesecretaría General Técnica del Ministerio de Igualdad, donde se decía que los anuncios periodísticos de servicios sexuales, aparte de implicar un trato vejatorio y degradante, «vulneran el valor fundamental de la igualdad entre mujeres y hombres, y pueden favorecer la transmisión de roles y estereotipos contrarios a dichos derechos y valores, y favorecedores de la violencia de género, por cuanto transmiten la idea de un género femenino sumiso, subordinado, servil e inferior».

Como señala el informe, la prostitución «es un fenómeno que tiene especial incidencia en el ámbito femenino (...) las mujeres se convierten en un objeto de consumo, asumiendo un rol (...) que las convierte en mercadería», no siendo para ello precisa ni siquiera «la inclusión en los anuncios de imágenes ni de cuerpos femeninos». Luego volveré sobre ello.

\section{IV.3. LA PROTECCIÓN DE LA JUVENTUD Y DE LA INFANCIA}

Sin duda se encuentra en el artículo 20.4 CE el principal fundamento de cualquier medida limitativa de la publicidad sobre prostitución que pretenda adoptarse: «el efecto sobre los menores puede ser perjudicial para su desarrollo personal —al posibilitar, en- 
tre otras cosas, llevarles a la creencia de que la prostitución es una opción profesional equiparable a las demás lícitas (...) el Consejo de Estado entiende que la conveniencia de impedir la difusión de una actividad simplemente tolerada y la protección debida a los menores, según el ordenamiento jurídico, amparan la adopción de las medidas prohibitivas de la publicación de anuncios de prostitución en prensa».

\section{IV.4. ¿ES LA PRÁCTICA PUBLICITARIA UNA MANIFESTACIÓN DE LA LIBERTAD DE EXPRESIÓN (ARTÍCULO 20 CE) O DE LA LIBERTAD DE EMPRESA (ARTÍ́CULO 38)?}

Es otra de las cuestiones a las que necesariamente había de referirse el Consejo de Estado. La relevancia de la pregunta tiene que ver con la idea de que las posibles restricciones de la libertad de expresión no debieran equipararse a las de la libertad de empresa. A la hora de establecer limitaciones a las libertades del artículo $20 \mathrm{CE}$ parece razonable que el legislador disponga de un margen de discrecionalidad menor que si se trata de limitar la libertad de empresa, dada la particular conexión de aquéllas con el principio democrático.

Nos recuerda el Consejo de Estado que la manera de entenderse esta cuestión en Europa y en Estados Unidos no ha sido totalmente coincidente.

Lo más relevante de la publicidad «no es el mensaje, sino el marco en el que se desarrolla — el mercado_ y la finalidad que persigue — mercantil— (...) y esta actividad mercantil es subsumible en el ámbito de la libertad de empresa». Si la publicidad no está protegida por la libertad de expresión, «cabe establecer amplios límites a su contenido». La jurisprudencia, tanto del Tribunal Constitucional como del Tribunal Supremo, también entiende que las restricciones sobre publicidad no lesionan las libertades del artículo $20 \mathrm{CE}$.

\section{IV.5. LA PONDERACIÓN DE LOS BIENES JURÍDICOS EN CONFLICTO. EL PRINCIPIO DE PROPORCIONALIDAD}

El Consejo de Estado llega a la conclusión de que una iniciativa como la que se le plantea, que consiste en limitar la publicidad de la prostitución en la prensa escrita, «no infringe ninguna de las posibles manifestaciones de esos derechos» (libertad de información y libertad de empresa). ${ }^{4}$

Existe, además, proporcionalidad «entre la medida que se plantea adoptar — la prohibición de la publicidad-y los bienes jurídicos a proteger», que, como hemos visto, son varios. Además, «la autorregulación y otros medios de fomento negativo se han mostrado manifiestamente insuficientes para lograr la desaparición de los anuncios en la prensa escrita», lo que hace todavía más proporcionada la medida.

4 Antes al contrario, «se conecta derechamente con lo dispuesto en el Protocolo para prevenir, reprimir y sancionar la trata de personas, especialmente mujeres y niños, que complementa la Convención de las Naciones Unidas contra la Delincuencia Organizada Transnacional de 15 de noviembre de 2000, ratificada por España». 
En definitiva, «tratar de limitar la difusión de una actividad tolerada pero no bien considerada por el ordenamiento mediante la prohibición de la publicidad de los anuncios constituye un fin legítimo y el medio empleado, la interdicción, resulta racional, razonable y proporcionado».

\section{LA PROSTITUCIÓN EN EL ORDENAMIENTO INFRACONSTITUCIONAL ESPAÑOL}

La normativa española en materia de prostitución se encuentra recogida principalmente en el Código Penal, aunque también existe normativa autonómica y local relacionada con las condiciones sanitarias o urbanísticas de los establecimientos donde se ejerce la prostitución.

Las sucesivas reformas legislativas que han tenido lugar en los últimos años en nuestro Código penal han culminado diseñando un ilícito penal de determinación a la prostitución cuando se ejerce violencia, intimidación, engaño o abuso de superioridad o de necesidad, o de especial vulnerabilidad de la víctima, que siempre se activa cuando los prostituidos son incapaces o menores, quedando, pues, al margen del reproche penal el libre ejercicio de la prostitución practicada voluntariamente por personas mayores de edad cuando no concurran esas circunstancias 5 .

\section{VI. ¿ES LA DICOTOMÍA RECOMENDABLE/NO RECOMENDABLE DE NATURALEZA JURÍDICA?}

Quien se acerca al tema de la prostitución desde una perspectiva jurídica se termina preguntando: ¿la dicotomía recomendable/no recomendable es de naturaleza jurídica?

Toda la estructura jurídica de un Estado de Derecho se sostiene sobre un pilar que se puede resumir en la siguiente frase: lo que no está prohibido en un régimen de libertades debe considerarse permitido.

Pero, aunque el ordenamiento jurídico tolere situaciones contrarias a los valores que sustentan a una sociedad, «no tiene por qué ser neutral ante ellas», dice el Consejo de Estado, de manera que «puede reaccionar limitando su existencia o mitigando su propagación», como ya hemos dicho.

El parámetro de lo lícito/ilícito, junto al parámetro de lo recomendable/no recomendable, formarían parte de ese doble eco tan característico de muchas instituciones del Derecho constitucional: el Tribunal Constitucional, interpretando y creando derecho; el parlamento, representando y siendo representativo.; etc.

5 Cfr. Código Penal, libro II, título VII bis «De la trata de seres humanos» y título VIII «Delitos contra la libertad e indemnidad sexuales», en particular el capítulo $\mathrm{V}$ «De los delitos relativos a la prostitución y la corrupción de menores». 
En cualquier caso, lo que aquí se está planteando es la legitimidad de una posible limitación o prohibición de esos contenidos publicitarios, es decir, la posibilidad —y no la obligatoriedad — de que el legislador pueda prohibirlos o limitarlos.

\section{COMENTARIO}

\section{VII.1. EL OBJETO}

El debate jurídico acerca de la prohibición de la publicidad de anuncios en materia de prostitución es, en el fondo, el debate sobre la prostitución. En realidad, hay más debates ahí, pero esencialmente es ese debate. De la dificultad para separar ambas cuestiones - prostitución y publicidad sobre prostitución - tampoco ha podido escapar el informe de la Comisión de Estudios del Consejo de Estado, aunque lo ha intentado: «el Consejo de Estado no cree necesario hacer consideraciones generales sobre el fenómeno de la prostitución», que luego termina haciendo.

Y no sólo existen dos debates, porque el problema de la prostitución, propiamente dicho, suscita nuevos debates sobre cuestiones colaterales como la trata de personas, la inmigración ilegal, el tráfico de drogas, el blanqueo de capitales, etc.

\section{VII.2. EL FUNDAMENTO}

A mi juicio, el fundamento más consistente para justificar una medida limitativa de la publicidad sobre prostitución, teniendo en cuenta que la publicidad no es una actividad ilícita ni tampoco la prostitución ejercida libremente (no así cuando concurren, como hemos visto, determinadas circunstancias), es el de la protección de la juventud y de la infancia (art. 20.4 CE).

\section{VII.3. LOS ARGUMENTOS}

El Consejo de Estado llega a la conclusión de que limitar la publicidad de la prostitución en la prensa escrita es una medida, no sólo constitucionalmente posible, sino también conveniente.

Lo importante en este tipo de cuestiones es saber qué sociedad queremos y qué Derecho queremos, qué valores defendemos y, sobre todo, hasta dónde estamos comprometidos con el valor de la dignidad humana.

Lo más relevante del informe no son, por tanto, sus argumentos jurídicos concretos, todo el caudal argumental que despliega, sino lo que el Consejo de Estado «quiere», su conclusión final, su punto de llegada, el modelo de sociedad al que nos invita con este completo informe.

¿Y cuáles serían esos otros argumentos que podrían ser utilizados para mantener una posición contraria a la adoptada por el Consejo de Estado? Por ejemplo, en relación con el argumento de la igualdad de género, cabría decir que no sólo las mujeres se anuncian 
en estas páginas, aparte de que, aunque la publicidad de la prostitución favorezca estereotipos de mujer incompatibles con la igualdad entre hombres y mujeres (artículo 14 $\mathrm{CE})$, lo mismo hace, salvando las distancias, la publicidad sexista de otros productos. O, por ejemplo, en relación con el favorecimiento de determinados estereotipos poco constructivos de mujer, se podría aducir que, aunque sea evidente que no se valora en este tipo de anuncios publicitarios a la mujer en función de sus cualidades intelectuales, sino de sus atributos físicos, no es algo que suceda sólo con los anuncios sobre prostitución, porque eso mismo ocurre, también salvando las distancias, en las campañas publicitarias de moda, de belleza, de lencería, de productos para adelgazar, etc. Y en relación con al argumento de la protección de la juventud y de la infancia, determinadas formas de pensar, que ni que decir tiene que no comparto, incidirían en que la prostitución existe como parte de la realidad, de manera que los menores deberían conocerla e ir aprendiendo poco a poco a gestionarla dentro de su libertad, de igual forma que no se prohíbe la información relacionada con la corrupción, la delincuencia, la insolidaridad, etc., por el simple hecho de que podría llegar toda esa información a los menores.

Frente al argumento, que también se ha utilizado a veces, de que preservando a la sociedad de la publicidad sobre la prostitución, la protegemos indirectamente del proxenetismo, del rufianismo, de la trata de seres humanos, etc., se podría decir que, puestos a prohibir, habría que impedir entonces todas aquellas actividades que pudieran dar lugar o no a una actividad ilícita, empezando por la actividad de los bancos, para prevenir la usura, o la de los establecimientos de ocio nocturno, para prevenir la venta de alcohol a menores, e incluso habría que cerrar hasta la propia Administración, a la vista de ciertos escándalos recientes y menos recientes.

Alguien habrá también que argumente, desde una extrema visión práctica de las cosas, que la prostitución se va a seguir produciendo, haya o no anuncios en los periódicos, y que, permitiendo éstos, al menos se paga un IVA y se proporcionan los datos de las personas que impulsan esas actividades, lo que puede facilitar a la postre la investigación policial de todas las actividades ilícitas relacionadas con la prostitución.

\section{VII.4. LA OPORTUNIDAD}

El otro problema del informe del Consejo de Estado (más bien del encargo gubernamental del informe, porque el informe lo que hace precisamente es ponerlo de manifiesto), es el relacionado con la oportunidad de la medida limitativa que se cuestiona. A estas alturas, plantear el tema de la prohibición de la publicidad de la prostitución en la prensa escrita es extemporáneo. Ahora, el enemigo contra el que quería luchar la medida gubernamental ya se encuentra en otro sitio, particularmente en internet. Es además en internet donde menos controles hay y donde la juventud y la infancia acceden más habitualmente.

Aparte de que, como advierte el propio informe de la Comisión de Estudios del Consejo de Estado, no dejaría de ser chocante que se prohibieran los anuncios de contactos en los periódicos, pero siguieran los de teléfonos eróticos o los de videoclubs pornográficos en los que no hay oferta de contactos carnales directos. Propone por eso el Consejo de Estado incluir todas esas actividades en el concepto funcional de publicidad de la prostitución que se incorporaría a la ley o, en última instancia, establecer en esa ley 
que «en ningún caso, podrán incluirse en ellos imágenes que presenten a las personas como meros objetos sexuales».

Dice por todo ello el Consejo de Estado en su Consideración Final que «aunque excede del ámbito del encargo recibido — que se ciñe a la posibilidad de prohibir los anuncios de prostitución en la prensa escrita- el Consejo de Estado debe señalar la conveniencia de ponderar la extensión de dicha prohibición a otros medios en el caso de que se estableciere aquélla».

\section{VII.5. LA PROSTITUCión EN EL ESTAdo SOCIAL Y DEMOCRÁtico De DERECHO}

En el Estado de Derecho históricamente han existido las llamadas «cloacas» o partes no visibles del mismo, en relación con determinados escarceos en la lucha antiterrorista, con las clínicas abortistas toleradas dentro de un marco legal prohibitivo, etc. En el ámbito del Estado democrático o participativo también han aparecido espacios opacos similares, relacionados por ejemplo con la financiación de los partidos políticos, con el papel político de los llamados lobbys y con otros asuntos. Y también encontramos en el ámbito del estado social ese tipo de espacios donde se encontrarían las contradicciones sociales que casi siempre han existido en torno al problema de la prostitución.

El Estado social y democrático de Derecho se resiste a reconocer la existencia de estos espacios opacos porque piensa que sin ellos brilla más la libertad. Y es verdad, pero también se hace más falsa.

El caso es que el Estado de Derecho siempre ha digerido mejor la falta de verdad que la falta de la estética de la libertad. Cuando se vio exigido siempre antepuso la estética, aun sabiendo que no mejoraría el enfermo retocando la radiografía.

El problema de la prostitución se encuentra a mitad de camino entre los problemas crónicos del Estado de Derecho y del Estado social. Viene a ser así uno de esos problemas que no nos permiten cerrar bien el círculo, un círculo al que los constitucionalistas hemos puesto nombre: el concepto unitario de estado social y democrático de derecho.

\section{VII.6. LA DECISIÓN}

Detrás de cada dictamen, de cada sentencia, de cada artículo doctrinal, etc., lo que existe, si se mira bien, es un acto emocional, que toma la falsa apariencia, al menos en parte, de ser un acto intelectivo basado en un buen razonamiento mental. Lo que quiero decir es que los juristas siempre encontramos razones para todo, no es difícil. La respuesta del Estado ante problemas como el de la prostitución y la publicidad de la prostitución no se encuentra en argumentos jurídicos, sino en nuestro compromiso con la dignidad y la solidaridad y con el tipo de sociedad que queremos y en la que nos reconocemos. En defensa de la publicidad de la prostitución podemos encontrar decenas de argumentos jurídicos, hemos visto algunos, que nos permitirán ganar millones de euros, que es lo que está ocurriendo, pero instrumentalizando a las personas, patrimonializándolas, convirtiéndose en meros objetos sexuales, no seremos una sociedad mejor, sino peor. 
$* * *$

TITLE: Prostitution, advertising and constitutional principles.

ABSTRACT: In March 2011 Consejo de Estado has said, answering to a goverment's question, that it is posible to enact a law in Spain that probibits or limits the advertisements about prostitution in the press. The author centre bis comments to the most relevant questions that, from a constitutional perspective, he arisenes the problem and agrees with the arguments adopted by Consejo de Estado.

Resumen: El Consejo de Estado llega a la conclusión de que es acorde con el Derecho español la adopción de medidas que coadyuven a la limitación de la publicidad sobre prostitución. Para ello recomienda la elaboración de una nueva ley, que no precisa ser ley orgánica, que incorpore un concepto específico de publicidad a los efectos de la propia disposición legal. El encargo se habia planteado al Consejo de Estado por Orden de la entonces Ministra de Igualdad de 12 de mayo 2010, sobre las posibilidades de actuación contra anuncios de contenido sexual y prostitución publicados a diario en la prensa escrita.El autor centra sus comentarios en las cuestiones más relevantes que, desde una perspectiva constitucional, plantea el problema, manifestándose en líneas generales coincidente con las tesis del Consejo de Estado.

KeYWORDs: «Consejo de Estado». Prostitution. Equality.

Palabras Clave: Consejo de Estado. Prostitución. Igualdad.

FECHA DE RECEPCIÓN: 16.07.2011. FECHA DE ACEPTACIÓN: 29.07.2011. 
